\title{
RESÍDUOS SÓLIDOS URBANOS: LEGISLAÇÃO E NOVOS DESAFIOS
}

Rodrigo Coladello Oliveira, Lucas Prado Osco, Marcos Norberto Boin, Munir Jorge Felicio

Universidade do Oeste Paulista. E-mail: rodcoladello@hotmail.com.

\section{RESUMO}

O presente trabalho teve como objetivo realizar um levantamento histórico e refletir como ocorreu a construção do aparato legal sobre os resíduos sólidos urbanos no Brasil e seus impactos ambientais. 0 embasamento teórico utilizado na pesquisa enfatizou-se nos resíduos sólidos, relacionando-os com o modo de vida consumista e com a crescente questão ambiental e populacional desde o final do século $X X$. Esta pesquisa contemplou revisão bibliográfica em livros, artigos, documentos científicos, legislações e manuais com o intuito de verticalizar os conhecimentos relativos ao tema. Os resultados obtidos demonstram que todo o avanço legislativo referente aos resíduos sólidos urbanos no Brasil, contribuiu para a elaboração da Política Nacional de Resíduos Sólidos (PNRS). Portanto, é perceptível que para obter uma melhor aplicabilidade da lei, no que diz respeito ao gerenciamento dos resíduos sólidos, a integração e estruturação da sociedade torna-se essencial.

Palavras-chave: Política Nacional de Resíduos Sólidos. Século XX. Meio Ambiente. Consumismo.

\section{INTRODUÇÃO E OBJETIVO}

O descarte incorreto dos resíduos sólidos ancorado a demanda crescente por consumo, mais do que colocar em risco os recursos naturais do planeta, nos forçou a buscar novas soluções para a problemática que nos aflige, pois conciliar as necessidades de consumo global de uma população que, em 2050 chegará aproximadamente a nove bilhões de habitantes, com as necessidades de regeneração do planeta, não será uma tarefa simples (INSTITUTO ETHOS, 2012).

Concomitante à expansão do sistema capitalista, a questão dos resíduos passou a ser considerada algo notável. Assim, Kligerman (2003 apud LEITE, 2006) pondera que:

Após a Revolução Industrial, surge a sociedade de consumo. Na sociedade de consumo, aumenta a necessidade de infra-estrutura (caminhões para transporte; locais para tratamento e destinação, como usina de reciclagem e compostagem, aterro sanitário), devido à crescente quantidade de lixo, mas também cresce a resistência à criação de locais para esta destinação devido ao incômodo, desvalorização do imóvel etc. (p. 101).

Vale ressaltar que o crescimento da população provocou uma imensa demanda sobre os recursos naturais, em especial nos países capitalistas ocidentais, onde as economias são pautadas pelo consumismo. Assim, criou-se um circulo vicioso de pressão sobre os recursos naturais, 
caracterizado por consumo desenfreado e pela geração de resíduos, mal este que a sociedade moderna não consegue desatrelar.

Em virtude disso, Bernardes e Ferreira (2003 apud LEITE, 2006) refletem:

A era moderna, fascinada pela produtividade com base na força humana, assiste ao aumento considerável do consumo, já que todas as coisas se tornam objetos a serem consumidos. Como membros de uma sociedade de consumidores, na atual fase do capitalismo, vivemos num mundo em que a economia se caracteriza pelo desperdício, onde todas as coisas devem ser devoradas e abandonadas tão rapidamente como surgem, em que as coisas surgem e desaparecem "sem jamais durarem o tempo suficiente para conter em seu meio o processo vital". (p. 21).

Ao mesmo tempo têm-se o processo de urbanização que de acordo com Pinho (2011), a geração de resíduos sólidos está principalmente relacionada com o processo civilizatório humano, pois desde que deixamos de ser nômades e passamos a nos fixar em territórios, começamos a conviver com os resíduos gerados por nossas próprias atividades.

Segundo Seadon (2006), nos primeiros núcleos habitacionais os resíduos oriundos dos habitantes eram lançados diretamente nas ruas ou nas imediações das residências, além disso, outra prática comum era promover a queima desses resíduos. Não era corriqueira a existência de líderes para a gestão dos resíduos e nem de lugares definidos para a disposição final, as estratégias de gestão eram particulares. Salvo a cidade de Mahenjo-Daro, no Vale Indu, onde se tem registros de gestão de resíduos no ano 2.000 a.C e, segundo Feitosa (2008), em alguns depósitos de lixo da época do império romano, onde ainda existem remanescentes de chorume.

Destaca-se que no Brasil cerca de $58,1 \%$ do total de resíduos sólidos urbanos coletados são destinados à aterros sanitários, porém aproximadamente 75 mil toneladas diárias são destinadas à aterros controlados e lixões, os quais são considerados métodos de disposição inadequado por não possuírem um conjunto de sistemas e medidas necessárias para garantir a proteção do meio ambiente contra os impactos causados pela disposição de resíduos sólidos, neste caso, urbanos (ABRELPE, 2011).

Apesar das Leis, instruções normativas e todas as outras determinações legais, essa destinação inadequada de resíduos sólidos urbanos está presente em todos os estados brasileiros. Em um panorama geral, mais de 60\% dos municípios até o ano de 2011, dispunham seus resíduos de maneira inadequada (ABRELPE, 2011). 


\section{METODOLOGIA}

O presente trabalho caracterizou-se por uma pesquisa bibliográfica, utilizando livros, legislações (Leis, Decretos, Resoluções e Normas), artigos e documentos científicos, tornando possível o levantamento histórico da geração de resíduos sólidos, sua relação no século XX com o modo de vida consumista e com a evolução da sociedade. Do mesmo modo, elaborou-se um histórico da legislação brasileira referente aos resíduos sólidos, nos âmbitos estadual e federal, permitindo analisar como ocorreu a construção do aparato legal sobre os resíduos sólidos urbanos no Brasil, bem como seus impactos ambientais. Por fim, elaborou-se uma discussão referente às práticas que levaram à construção do aparato legislativo voltado para os resíduos sólidos urbanos.

Durante o levantamento bibliográfico, algumas referências foram retiradas de publicações científicas disponíveis na internet e outras referências disponíveis em periódicos e livros referentes aos assuntos aqui tratados. Essa pesquisa é de suma importância e substancial para um futuro estudo longitudinal sobre a temática supracitada.

\section{RESULTADOS}

Na segunda metade do século XX, com a criação da Política Nacional do Meio Ambiente (PNMA), Lei no 6.938/81, já se preocupava com a preservação, melhoria e recuperação da qualidade ambiental propícia à vida, visando assegurar, no país, condições ao desenvolvimento sócioeconômico, aos interesses da segurança nacional e à proteção da dignidade da vida humana.

Portanto, tratando-se de resíduos sólidos, no anexo VIII da PNMA, código 17, consideram-se atividades potencialmente poluidoras e utilizadoras de recursos ambientais aquelas que envolvem:

\footnotetext{
"Produção de energia termoelétrica; tratamento e destinação de resíduos industriais líquidos e sólidos; disposição de resíduos especiais tais como: de agroquímicos e suas embalagens; usadas e de serviço de saúde e similares; destinação de resíduos de esgotos sanitários e de resíduos sólidos urbanos, inclusive aqueles provenientes de fossas; dragagem e derrocamentos em corpos d'água; recuperação de áreas contaminadas ou degradadas".
}

Começara então, com a PNMA, a construção do aparato legal sobre os resíduos sólidos no Brasil. Posteriormente, tem-se a criação da Constituição Federal (C.F.) de 1988, a qual de maneira indireta em seu artigo 225 faz referência aos resíduos sólidos, prevendo que: 
"Todos têm direito ao meio ambiente ecologicamente equilibrado, bem de uso comum do povo e essencial à sadia qualidade de vida, impondo-se ao Poder Público e à coletividade o dever de defendê-lo e preservá-lo para as presentes e futuras gerações".

Outrossim, o art. 23, VI, atribui competência a União, aos Estados, ao Distrito Federal e aos municípios em "proteger o meio ambiente e combater a poluição em qualquer de suas formas". Deste modo, as esferas supracitadas receberam autonomia suficiente para elaboração de normas e leis específicas em seus respectivos âmbitos, de modo que atendesse as necessidades e exigências locais.

No final do século XX, em 12 de fevereiro de 1998 foi elaborada a Lei $n$ ㅇ 9.605, onde em seu caput dispõe sobre sanções penais e administrativas derivadas de atitudes ou condutas lesivas ao meio ambiente. Em seu Art. 54, §2으, V, faz referência ao lançamento inadequado de resíduos sólidos como um ato de crime ambiental e passível de punição.

No ano de 2002, criou-se a Resolução CONAMA no 308 de 21 de março, servindo de suporte técnico no sentido de propor formas adequadas de disposição final dos resíduos sólidos urbanos em pequenos municípios, além de apontar critérios e diretrizes para o licenciamento ambiental de aterro sanitário de pequeno porte.

Desde então surgiram Leis específicas para os tipos de resíduos, em especial após a criação da Norma Brasileira - NBR 10.004/04, na qual fornece critérios de classificação para os resíduos sólidos quanto a sua periculosidade ao meio ambiente e à saúde pública. Além disso, tal norma auxilia para o gerenciamento adequado dos diversos tipos de resíduos.

De acordo com a Secretaria do Meio Ambiente (2013), o estado de São Paulo possui, desde 2006, um vasto conjunto de princípios, diretrizes e instrumentos de gestão dos resíduos sólidos, os quais estão contidos na Lei Estadual no 12.300, de 16 de março de 2006 que institui a Política Estadual de Resíduos Sólidos (PERS). O grande avanço dessa política se deu na combinação dos princípios da responsabilidade pós-consumo; poluidor pagador; resíduos sólidos reutilizáveis e recicláveis, como um bem econômico na geração de trabalho e renda. Além disso, a PERS propicia uma visão sistêmica na gestão dos resíduos; ao considerar as variáveis sociais, econômicas, tecnológicas, culturais, ambientais e de saúde pública. Por fim, destaca-se na PERS a elaboração de padrões sustentáveis de produção e consumo, a gestão integrada e compartilhada dos resíduos 
sólidos. A PERS é considerada pioneira dentre as legislações que tratam dos resíduos sólidos servindo de subsídios para a elaboração da Política Nacional de Resíduos Sólidos.

Em 2007 foi criada a Política Nacional de Saneamento Básico, instituída na Lei 11.445/07, a qual em seu Art. 2ํㅡ, III, considera as formas adequadas de manejo dos resíduos sólidos como forma de serviço público de saneamento, igualando-se aos serviços de abastecimento de água e tratamento de esgotos. Dentre os resíduos sólidos, destacam-se aqui os resíduos de origem urbana, cujo suas formas de manejo previstas em Lei são: "conjunto de atividades, infra-estruturas e instalações operacionais de coleta, transporte, transbordo, tratamento e destino final do lixo doméstico e do lixo originário da varrição e limpeza de logradouros e vias públicas".

No ano de 2008, criou-se a Resolução CONAMA no 404 de 11 de novembro, na qual revoga a CONAMA no 308/02 e propõe apenas algumas atualizações, como por exemplo, ao considerar um aterro sanitário de pequeno porte aquele que recebe diariamente até 20 toneladas de resíduos sólidos urbanos.

Recentemente após 20 anos de discussão no congresso, foi aprovada em 2 de agosto de 2010 a Lei 12.305/10, onde institui a Política Nacional de Resíduos Sólidos (PNRS), regulamentada pelo Decreto no 7.404, de 23 de dezembro de 2010. A Lei exibe vários pontos significativos para a gestão e o gerenciamento de resíduos sólidos no Brasil, obedecendo rigorosamente a seguinte ordem: não geração, redução, reutilização, reciclagem, tratamento dos resíduos sólidos e por fim a disposição final ambientalmente correta (SECRETARIA DO MEIO AMBIENTE, 2013).

Portanto, todo esse conjunto de Leis, Normas e Resoluções ajudaram a construir um aparato legal para a elaboração da Política Nacional de Resíduos Sólidos de maneira sistêmica e abrangente, mantendo a consonância com a Constituição Federal, permeando de maneira indireta e compatível em Leis como a Política Nacional de Saneamento Básico (Lei no. 11.445/07). Todo esse aparato legal faz da PNRS uma lei moderna e de instrumentos inovadores, destacando a responsabilidade compartilhada e a contemplação da inclusão social dos catadores.

\section{DISCUSSÃO}

A necessidade da construção de todo esse aparato legal sobre os resíduos sólidos deuse após a revolução industrial (Séculos XVII e XVIII), onde se estabelecia uma economia industrializada, pautada pelo consumo, centrada no espaço urbano e altamente consumidora de 
energia e matérias primas. Consequentemente, os impactos relacionados aos resíduos sólidos aumentaram proporcionalmente.

Considera-se que a geração dos resíduos sólidos urbanos é eminente, além de um dos grandes desafios das sociedades contemporâneas em dar destinação correta a estes resíduos, visto que no Brasil $80 \%$ da população vivem em cidades. Isto posto, devido à aglomeração de habitantes nas zonas urbanas, os resíduos atualmente gerados são de maior periculosidade e complexidade (JACOBI, 2012).

O Brasil, de acordo com Maricato (2002 apud LEITE, 2006), apresentou intenso processo de urbanização, em especial na segunda metade do século XX. Cerda e Cúneo (1999, p. 11 12 apud LEITE, 2006) alertam para os problemas que podem emergir desse acentuado processo de urbanização citado anteriormente:

Os problemas decorrentes de deficiências no saneamento básico seguem minando a saúde de milhões de pessoas. É necessário resolver esses problemas e, consequentemente, avançar para controlar a crescente exposição das pessoas a perigos tais como a contaminação do ambiente por resíduos derivados da atividade humana, assim como a um número cada vez maior de substâncias tóxicas com as quais se tem contato diário. (...) A contínua urbanização, associada à expansão industrial, tanto urbana como rural, transformou-se num problema crescente para a saúde pública e requer intervenção antes que se torne incontrolável.

A partir do pressuposto de que, após a revolução industrial, passou a ser comum encontrar pessoas que retiram dos resíduos sólidos a sua principal fonte de renda, os impactos causados por estes são diversos e vão desde uma dimensão sociocultural e antropológica, até aos impactos ambientais e sanitários, os quais exigem rigorosa consideração (SANTOS \& ; DIAS, 2012).

Para minimizar os impactos causados pelos resíduos sólidos urbanos, os governos Federal e Estadual aplicam leis que aperfeiçoam o gerenciamento dos resíduos, bem como sua disposição final. Devido a crescente complexidade desses resíduos, agravado pela expansão populacional no final do ultimo século, houve necessidade das leis referentes a estes se atualizarem e tornarem-se cada vez mais sistêmicas e abrangentes, como por exemplo, a PNRS, Lei 12.305/2010. No âmbito específico do oeste paulista a proposição de coleta seletiva e a criação de uma rede de reciclagem solidaria de resíduos sólidos, baseada na Política Nacional de Resíduos Sólidos, a ser implantado em 56 (cinquenta e seis) municípios, com o apoio da UNESP, UNOESTE, Ministério Público 
Federal, Estadual e a CESP, pode se tornar um cenário ideal para o desenvolvimento de modelos de políticas públicas planejadas e integradas, que visem atender às demandas da população, o que possibilitará corrigir distorções, bem como resguardar o meio ambiente e a saúde pública, para as presentes e futuras gerações, adequando-se ao princípio da solidariedade inter e intrageracional.

\section{CONCLUSÃO}

Conclui-se que toda a discussão que se fez sobre o meio ambiente desde o final do século XX, contribuiu para maior reflexão sobre a apropriação dos recursos naturais e consequentemente para o surgimento de leis que buscam a proteção e conservação do meio ambiente no Brasil, bem como para a criação de normas aplicáveis ao gerenciamento integrado dos resíduos sólidos. Todo esse desenvolvimento da legislação ambiental no Brasil desde o último século colaborou para que pudesse chegar ao mais próximo da abordagem sistêmica em sua aplicabilidade, a exemplo da PNRS.

Por fim, vale ressaltar que para uma mudança comportamental e uma quebra de paradigma, é de extrema importância a estruturação e a integração da sociedade como sendo à base de qualquer planejamento, assim como está sendo realizado no oeste paulista com o projeto de coleta seletiva de resíduos sólidos urbanos e a rede de reciclagem solidária.

\section{REFERÊNCIAS}

ABNT - $\quad$ Associação Brasileira de Normas $\quad$ Técnicas. NBR 1004 Resíduos Sólidos - Classificação. Rio de Janeiro, Setembro/1987. 63 p.

ABRELPE. Panorama dos Resíduos Sólidos no Brasil. São Paulo: Abrelpe. 2011.

BERNARDES, J. A. e FERREIRA, F. P. de M. Sociedade e Natureza. In CUNHA, S. B. e GUERRA, A. J. T. (orgs). A questão ambiental: diferentes abordagens. Rio de Janeiro: Bertrand Brasil, 2003.

BRASIL. Constituição (1988). Constituição da República Federativa do Brasil. Brasília, DF: Senado Federal: Centro Gráfico, 1988. 292 p.

. Decreto Federal no 98816, 11 de janeiro de 1990. Regulamenta a Lei 7802, de 11 de julho de 1989, que dispõe sobre a pesquisa, a experimentação, a produção, a embalagem e rotulagem, o transporte, o armazenamento, a comercialização, a propaganda comercial, a utilização, a importação, a exportação, o destino final dos resíduos e embalagens, o registro, a classificação, o controle, a inspeção e a fiscalização de agrotóxicos, seus componentes e afins, e dá outras providências. Brasília: Ministério da Agricultura, Departamento de Defesa e Inspeção Ambiental, p.15-53, 1998. 
. Lei no 6.938, de 31 de agosto de 1981. Dispõe sobre a Política Nacional do Meio Ambiente, seus fins e mecanismos de formulação e aplicação, e dá outras providências.

. Lei no 9.605, de 12 de fevereiro de 1998. Dispõe sobre as sanções penais e administrativas derivadas de condutas e atividades lesivas ao meio ambiente, e dá outras providências.

- Lei 11.445 , de 5 de janeiro de 2007. Estabelece diretrizes nacionais para o saneamento básico; altera as Leis nos 6.766, de 19 de dezembro de 1979, 8.036, de 11 de maio de 1990, 8.666, de 21 de junho de 1993, 8.987, de 13 de fevereiro de 1995; revoga a Lei no 6.528, de 11 de maio de 1978; e dá outras providências.

Lei 12.305, de 2 de agosto de 2010. Institui a Política Nacional de Resíduos Sólidos; altera a Lei no 9.605, de 12 de fevereiro de 1998; e dá outras providências.

. Constituição da República Federativa do Brasil de 1988.

FEITOSA, F. A. C. Hidrogeologia: conceitos e aplicações. CPRM, 2008.

INSTITUTO ETHOS. Política Nacional de Resíduos Sólidos: Desafios e Oportunidades para as Empresas. São Paulo: Instituto Ethos, 2012.

LEITE, DJANE A. BARBOSA. Política pública municipal de resíduos sólidos: diagnóstico do contrato de concessão de serviços públicos de limpeza urbana em fortaleza. 2006. 139 f. Dissertação (Mestrado em Desenvolvimento e Meio Ambiente) - Universidade Federal do Ceará. Fortaleza.

PINHO, P. M. Avaliação dos planos municipais de gestão integrada de resíduos sólidos urbanos na Amazônia brasileira. Tese (Doutorado Programa de Pós-Graduação em Ciência Ambiental) Universidade de São Paulo. São Paulo, 2011.

SANTOS, M. C LOSCHIAVO; DIAS S. L. F. GONÇALVES. Resíduos sólidos urbanos e seus impactos socioambientais. (orgs.). São Paulo: IEE-USP, 2012. 82p.

SÃO PAULO. Lei Estadual no 12.300 de 16 de março de 2006. Institui a Política Estadual de Resíduos Sólidos e define princípios e diretrizes.

SEADON, J.K. Integrated waste management-looking beyond the solid waste horizon. Waste Management: 2006: 26: 1327-1336.

SECRETARIA DO MEIO AMBIENTE. Resíduos Sólidos. 2oed. São Paulo: SMA, 2013. 